\title{
Triplet cytotoxic chemotherapy with gemcitabine, 5-fluorouracil and cisplatin for advanced pancreatic cancer
}

\author{
BYEONG SEOK SOHN ${ }^{1}$, YOUNG JIN YUH ${ }^{1}$, HONG SUK SONG ${ }^{2}$, \\ BONG-SEOG KIM ${ }^{3}$, KYUNG HEE LEE ${ }^{4}$, JOUNG-SOON JANG ${ }^{5}$ and SUNG ROK KIM ${ }^{1}$ \\ ${ }^{1}$ Department of Internal Medicine, College of Medicine, Inje University Sanggye Paik Hospital, Seoul 139-707; \\ ${ }^{2}$ Department of Hematooncology, Dongsan Medical Center, Keimyung University School of Medicine, Daegu 700-712; \\ ${ }^{3}$ Department of Internal Medicine, Veterans Health Service Medical Center, Seoul 139-707; ${ }^{4}$ Division of Oncology, \\ Department of Internal Medicine, Yeungnam University College of Medicine, Daegu 702-701; \\ ${ }^{5}$ Division of Hematology/Oncology, Department of Internal Medicine, Chung-Ang University College of Medicine, \\ Seoul 139-707, Republic of Korea
}

Received September 4, 2014; Accepted May 20, 2015

DOI: $10.3892 / \mathrm{ol} .2015 .3347$

\begin{abstract}
In advanced or relapsed pancreatic cancer, mono- or duo-therapy has shown modest efficacy at best. The present study evaluated the efficacy of a triplet combination in relapsed or advanced pancreatic cancer. A total of 37 patients with adenocarcinoma of the pancreas in stage III/IV or with relapsed disease were treated with a gemcitabine, 5-fluorouracil and cisplatin (GFP) regimen every 3 weeks. Only 29 out of 37 patients were evaluable for response due to early treatment interruption in 8 patients. The overall response rate was $24.1 \%$ and the disease control rate was $68.9 \%$. The progression-free survival (PFS) rate was 61.5, 30.9 and $17.6 \%$ at 3, 6 and 9 months, respectively, and the overall survival (OS) rate was 46.5 and $30.6 \%$ at 6 and 12 months, respectively. Grade 3/4 leukopenia, neutropenia and thrombocytopenia occurred in $18.4,29.9$ and $24.5 \%$ of 147 cycles, respectively. Old age and a poor performance status (PS) were associated with the early discontinuation of chemotherapy $(\mathrm{P}=0.038$ and $\mathrm{P}=0.036$, respectively). In patients $<65$ years old and with a PS of $<2$, the median PFS and OS times were 5.3 months and 10.3 months, respectively. Overall, although GFP resulted in acceptable response and survival rates, it does not appear to have marked superiority to gemcitabine-based single or duplet chemotherapy.
\end{abstract}

Correspondence to: Dr Sung Rok Kim, Department of Internal Medicine, College of Medicine, Inje University Sanggye Paik Hospital, 761-1 Sanggye-7-dong, Nowon-gu, Seoul 139-707, Republic of Korea

E-mail: srkjoy@naver.com

Key words: pancreatic cancer, gemcitabine, cisplatin, 5-fluorouracil, response, overall survival

\section{Introduction}

Advanced pancreatic cancer has a poor prognosis with a median survival time of 3-5 months, which has not been changed in the era of 5-fluorouracil (5-FU) chemotherapy (1). The emergence of the nucleoside analogue gemcitabine has improved the response rate and clinical benefits compared with 5-FU monotherapy. However, the median survival time of affected patients remains at $\sim 6$ months (2-4).

As there are few other agents active against pancreatic cancer, numerous efforts have sought to improve the efficacy of combination regimens for this dismal disease. In previous studies, the combination of gemcitabine+irinotecan or gemcitabine+docetaxel showed an overall response rate in the range of $10-20 \%$, however, the overall survival (OS) time was not improved beyond 6 months (5-7). The combination of gemcitabine plus 5-FU with or without leucovorin showed an overall response rate in the range of 5-25.9\%, however, the OS time was in the range of 6.7-10.3 months (8-10).

In one study, cisplatin therapy produced a response rate of $21 \%$, with a median duration of response of 4 months (11). Use of a combination of gemcitabine and cisplatin produced a response rate of $11-26.4 \%$, which was better than gemcitabine only, and the median survival time was 7.1-8.2 months (12-14). Gemcitabine acts synergistically with 5-FU and with cisplatin (15-20). 5-FU acts synergistically with cisplatin (21). This suggests that these three agents may exhibit a triple-synergic effect on advanced pancreatic cancer.

With the expectation of synergism based on these previous studies, the present study investigated the efficacy and toxicities of a combination chemotherapy using a gemcitabine, 5-FU and cisplatin (GFP) regimen for the treatment of patients with advanced pancreatic cancer.

\section{Patients and methods}

Eligibility. The inclusion criteria were as follows: Patients with unresectable, relapsed or metastatic adenocarcinoma 
of the pancreas (American Joint Committee on Cancer stage III or IV) (22); at least one measurable lesion (defined as a mass with clearly demarcated dimensions on computed tomography, routine chest X-ray or physical examination); no prior chemotherapy or radiotherapy (lesions outside of the prior radiation port was acceptable); Eastern Cooperative Oncology Group performance status (ECOG PS) of 2 or better (23); age between 18 and 70 years; no concurrent uncontrolled medical illness; no other malignancies (with the exception of squamous cell carcinoma of the skin treated by surgery); total bilirubin $\leq 2$ times the upper normal limits (UNL), transaminases $\leq 3$ times the UNL and alkaline phosphatase $\leq 2.5$ times the UNL; adequate bone marrow function (hemoglobin, $\geq 9 \mathrm{~g} / \mathrm{dl}$; granulocytes, $\geq 1,800 / \mu 1$; and platelets, $\geq 100,000 / \mu 1$ ); and no other serious organ failure. A complete history was taken and a physical examination was performed on all patients prior to treatment. A cancer antigen (CA)19-9 test, electrocardiography, chest X-ray and abdominal computed tomography (CT) scan were performed. Signed informed consent was obtained from all patients prior to chemotherapy. The present study was based on the data from an initial single center study conducted by Inje University Sanggye Paik Hospital (Seoul, Korea), which was approved by the ethics committee of Inje University Saggye Paik Hospital.

Treatment methods. For each patient, $800 \mathrm{mg} / \mathrm{m}^{2}$ gemcitabine was intravenously infused in $\mathrm{D}_{5} \mathrm{~W}$ solution or $100 \mathrm{ml}$ normal saline $(\mathrm{N} / \mathrm{S})$ at $10 \mathrm{mg} / \mathrm{m}^{2} / \mathrm{min}$ on day 1 (D1) and day 8 (D8). 5-FU was continuously infused over $24 \mathrm{~h}$ at a dose of $800 \mathrm{mg} / \mathrm{m}^{2} /$ day in $\mathrm{D}_{5} \mathrm{~W}$ or N/S 11 on D1 through D4. Cisplatin $\left(60 \mathrm{mg} / \mathrm{m}^{2}\right)$ was infused for $3 \mathrm{~h}$ on D2, with a $24-\mathrm{h}$ interval after the start of gemcitabine infusion. The treatment was repeated every 3 weeks.

Complete blood cell counts (CBCs) were checked between D8-15 and whenever necessary to check the nadir blood cell counts thereafter. $\mathrm{CBCs}$, and serum calcium, creatinine, liver enzyme and electrolyte levels were checked prior to commencing each treatment cycle. The dose and treatment interval were adjusted based on the following criteria: The chemotherapy was continued when the D1 granulocyte and platelet count were $\geq 1,800 / \mu 1$ and $\geq 100,000 / \mu 1$, respectively. If not, the chemotherapy was delayed for 1 week. If the chemotherapy was delayed for longer than 2 weeks prior to hematological recovery, the study was discontinued. In cases where a nadir granulocyte count of $<500 / \mu 1$ or a platelet count of $<25,000 / \mu 1$ was observed during the previous cycle, the dose of gemcitabine and cisplatin was reduced by $10 \%$ in the next cycle. The reduction was allowed only once unless the patient experienced serious infection and/or hemorrhage. On each successive D8, 100\% of gemcitabine was administered in cases where granulocytes recovered to $\geq 1,000 / \mu 1$ and platelets recovered to $\geq 100,000 / \mu 1$. When the $\mathrm{D} 8$ granulocyte count was $500-999 / \mu 1$ and/or the platelet count was $50,000-99,000 / \mu 1$, the D8 dose of gemcitabine was reduced to half. Furthermore, if the granulocyte and/or platelet counts were $<500 / \mu 1$ and $<50,000 / \mu 1$, respectively, the D8 dose of gemcitabine was administered 1 week later when the above criteria were met; otherwise, the D8 dose of gemcitabine was skipped. During the chemotherapy, granulocyte/macrophage-colony stimulating factor (G/M-CSF) use was allowed according to the clinician's decision, while prophylactic use was not allowed. When the creatinine clearance was between $30-50 \mathrm{ml} / \mathrm{min}$, the dose of cisplatin was reduced to half; cisplatin was discontinued if the creatinine clearance was $<30 \mathrm{ml} / \mathrm{min}$, and the study was discontinued.

For grade 3/4 stomatitis or diarrhea, 5 -FU was reduced by $25 \%$. If the grade $3 / 4$ toxicity was observed again in the next cycle, the study was discontinued. When grade 3/4 neurotoxicity (intolerable paresthesia and/or marked motor function loss) occurred, cisplatin was discontinued and the patient was taken off the protocol.

Response and toxicity evaluation. A physical examination and chest X-ray was performed every cycle prior to commencing chemotherapy. An abdominal CT scan was repeated prior to every 2 cycles of chemotherapy or any time disease progression was suspected. Blood chemistry and CBCs were also checked every cycle prior to chemotherapy. If the level of CA19-9 was high prior to treatment, the tumor marker was checked every cycle prior to the next chemotherapy.

Response and toxicity were evaluated according to WHO criteria (24). Complete response (CR) was defined as disappearance of all measurable or evaluable disease, signs, symptoms, and biochemical change related to tumor for at least 4 weeks. A partial response (PR) was defined as a reduction of $\geq 50 \%$ in the sum of the products of two perpendicular diameters of all measured lesions lasting $\geq 4$ weeks. Stable disease (SD) was defined as $<50 \%$ reduction and $<25 \%$ increase in the sum of the products of all measurable lesions without appearance of new lesion. Progressive disease was defined as the appearance of any new lesion or definite increase in tumor size and a $>25 \%$ increase in the sum of the products of all measured lesions.

Treatment was continued until tumor progression or unacceptable toxicity occurred. Toxicity was evaluated prior to each cycle of therapy. The duration of response or SD was measured from the beginning of treatment until the documentation of progression. The response assessment was performed every 2 cycles of chemotherapy.

Statistics. The primary objective of the study was to examine the response rate and toxicity. The secondary objectives were to examine progression-free survival (PFS) and OS. The response rate of the gemcitabine/cisplatin combination for advanced pancreatic cancer patients has been recorded at $10-30 \%$ (12-14). If $40 \%$ was used as an expected response rate, $20 \%$ as a minimal acceptable response rate and $10 \%$ as a drop-out rate, 33 patients were required as a minimum, according to the Fleming one-stage procedure $\left(\mathrm{P}_{1}-\mathrm{P}_{0}=0.20\right.$, $\alpha=0.05, \beta=0.2)(25)$.

Proportions and categorical data were compared using Fisher's exact test. Continuous data were compared using Student's t-test or the Mann-Whitney U test. PFS time was calculated from the date of the initial treatment to the date of disease progression or any cause of mortality. OS time was calculated from the date of the initial treatment until mortality. Survival curves were estimated using the Kaplan-Meier method and compared with the log-rank test and Breslow test. All statistical analyses were performed using SAS version 9.1 (Cary, NC, USA). All analyses were two-sided and statistically significant differences were defined by a P-value of $<0.05$. 
Table I. Patient characteristics.

\begin{tabular}{|c|c|}
\hline Characteristic & Value \\
\hline Median age (range), years & $61(40-70)$ \\
\hline \multicolumn{2}{|l|}{ Gender, n (\%) } \\
\hline Male & $27(73.0)$ \\
\hline Female & $10(27.0)$ \\
\hline \multicolumn{2}{|l|}{ Performance status, n (\%) } \\
\hline $0-1$ & $26(70.3)$ \\
\hline 2 & $11(29.7)$ \\
\hline \multicolumn{2}{|l|}{ Disease status, n (\%) } \\
\hline Unresectable/metastatic & $5 / 27(13.5 / 73.0)$ \\
\hline Recurrent & $5(13.5)$ \\
\hline \multicolumn{2}{|l|}{ Previous treatment, $\mathrm{n}(\%)$} \\
\hline No previous treatment & $28(75.7)$ \\
\hline Palliative surgery & $4(10.8)$ \\
\hline $\begin{array}{l}\text { Surgery } \pm \text { adjuvant chemo- and/or } \\
\text { radiotherapy }\end{array}$ & $5(13.5)$ \\
\hline \multicolumn{2}{|l|}{ Primary sites, n (\%) } \\
\hline Head & $16(43.2)$ \\
\hline Body and tail & $21(56.8)$ \\
\hline \multicolumn{2}{|l|}{ Metastatic site, n (\%) } \\
\hline Liver & $20(54.1)$ \\
\hline Distant lymph node & $19(51.4)$ \\
\hline Peritoneum & $14(37.8)$ \\
\hline Lung & $6(16.2)$ \\
\hline
\end{tabular}

Table II. Overall best response in the 29 evaluable patients.

\begin{tabular}{lc}
\hline Response & Value \\
\hline Complete response, n (\%) & $0(0.0)$ \\
Partial response, $\mathrm{n}(\%)$ & $7(24.1)$ \\
Stable disease, $\mathrm{n}(\%)$ & $13(44.8)$ \\
Progressive disease, $\mathrm{n}(\%)$ & $9(31.0)$ \\
ORR, \% (95\% CI) & $24.1(12.2-42.1)$ \\
DCR, \% (95\% CI) & $69.0(50.8-82.7)$ \\
\hline ORR, overall response rate; DCR, disease control rate; CI, confidence \\
interval. ${ }^{a}$ Early mortality in 5 patients prior to evaluation, early dis- \\
continuation in 3 patients due to adverse events and/or other diseases \\
(cerebral infarct, lethargy and pneumonia).
\end{tabular}

\section{Results}

Patient characteristics. Between April 2002 and March 2009, 37 patients were enrolled into this study. The median age was 61 years old (range, 40-70 years old). The patient characteristics are shown in Table I. In total, 26 (70.3\%) patients showed an ECOG PS grade of 0-1 and 11 patients (29.7\%) showed a grade of 2. A total of 8 patients underwent a percutaneous transhepatic biliary drainage procedure due to obstructive jaundice prior to chemotherapy. After the completion of the study, 29 patients were evaluable and 8 patients dropped out early without the assessment of response.

Dose intensity of treatment drugs. A total of 153 cycles of treatment were administered, with a median of 3 cycles per patient (range, 1-12 cycles), and the dose intensity data was available in 147 cycles. D1 gemcitabine was administered at $97.8 \%$ during the 147 cycles of chemotherapy, D8 gemcitabine was administered at $75.0 \%$, cisplatin was administered at $96.9 \%$ and 5-FU was administered at $97.6 \%$. Among the 8 patients who could not be evaluated, a total of 10 cycles were administered, with a median of 1 cycle per patient (range, 1-2 cycles). During the 10 cycles, D8 gemcitabine was omitted in 3 cycles and reduced to the half dose in 2 cycles.

Treatment response and outcomes. Among the 29 patients evaluable for the response, 7 (24.1\%) patients exhibited a PR and $13(44.8 \%)$ patients experienced SD (Table II). The overall response rate was $24.1 \%$ [95\% confidence interval (CI), 12.2-42.1) and the disease control rate was $69.0 \%$ (95\% CI, 50.8-82.7). The median PFS and OS times of the evaluable patients were 4.1 months (95\% CI, 3.0-5.2) and 6.6 months (95\% CI, 4.9-8.2), respectively. The median PFS and OS times of all enrolled patients were 3.9 months (95\% CI, 2.4-5.4) and 5.8 months (95\% CI, 4.8-6.8), respectively (Fig. 1A and B). The PFS rate of all enrolled patients was $61.5 \pm 8.5,30.9 \pm 9.0$ and $17.6 \pm 7.7 \%$ at 3,6 and 9 months, respectively. A total of 10 patients underwent second-line therapy after progression. The most frequently used regimen was an oral 5-FU derivative-based regimen in 9 patients. The OS rate was $46.5 \pm 8.4$ and $30.6 \pm 8.0 \%$ at 6 and 12 months, respectively. The response rate and OS time were not associated with any clinical factors, including age ( $<65$ vs. $\geq 65$ years) and PS (<2 vs. $\geq 2$ ) (both $\mathrm{P}=1.000$ ).

Safety. During the 153 cycles of chemotherapy, toxicity was observed in 147 cycles (Table III). Grade 3/4 leukopenia, neutropenia and thrombocytopenia were documented in $18.4,29.9$ and $24.5 \%$ of 147 cycles, respectively. Grade 3/4 oral mucositis was observed in $4.1 \%$ of patients and grade 3 nausea/vomiting and diarrhea in 2.0 and $1.4 \%$ of 147 cycles, respectively. The incidence of grade $3 / 4$ neutropenia (the total number of grade $3 / 4$ neutropenia/total received cycles of each patient) and grade 3/4 thrombocytopenia (the total number of grade 3/4 thrombocytopenia/total received cycles of each patient) were associated with PS at diagnosis. The poor PS (PS of 2) was associated with a higher incidence of grade 3/4 neutropenia $(\mathrm{P}=0.009)$ and grade $3 / 4$ thrombocytopenia $(\mathrm{P}=0.006)$ compared with a PS of $0 / 1$. Although the elderly ( $\geq 65$ years) more frequently exhibited a poor PS [PS of $2 ; 4$ out of $9(44.4 \%)$ patients], this was not statistically significant $(\mathrm{P}=0.571)$. Also, the incidence of neutropenia and thrombocytopenia was not associated with age $(\mathrm{P}=0.468$ and $\mathrm{P}=0.906$, respectively).

In the 8 patients whose response could not be assessed due to early treatment interruption prior to first response evaluation, 5 of the patients succumbed prior to the first response evaluation (3 to sepsis, 1 to pneumonia and 1 to demyelinating disease), and 3 patients were taken off the study due to adverse events or other diseases (lethargy, cerebral infarct and pneumonia). 
Table III. Toxicity profiles observed in 147 cycles.

\begin{tabular}{|c|c|c|c|c|}
\hline \multirow[b]{2}{*}{ Toxicity } & \multicolumn{2}{|c|}{ Observed cycles, n (\%) } & \multicolumn{2}{|c|}{ Observed patients, n (\%) } \\
\hline & Grade 3 & Grade 4 & Grade 3 & Grade 4 \\
\hline \multicolumn{5}{|l|}{ Hematological } \\
\hline Anemia & $13(8.8)$ & - & $7(18.9)$ & \\
\hline Leukopenia & $22(15.0)$ & $5(3.4)$ & $12(32.4)$ & $5(13.5)$ \\
\hline Neutropenia & $26(17.7)$ & $18(12.2)$ & $9(24.3)$ & $14(37.8)$ \\
\hline Thrombocytopenia & $20(13.6)$ & $16(10.9)$ & $8(21.6)$ & $12(32.4)$ \\
\hline \multicolumn{5}{|l|}{ Non-hematological } \\
\hline Nausea/vomiting & $3(2.0)$ & - & $3(8.1)$ & \\
\hline Mucositis & $4(2.7)$ & $2(1.4)$ & $3(8.1)$ & $2(5.4)$ \\
\hline Diarrhea & $2(1.4)$ & - & $1(2.7)$ & \\
\hline Neuropathy & - & - & & \\
\hline
\end{tabular}

A

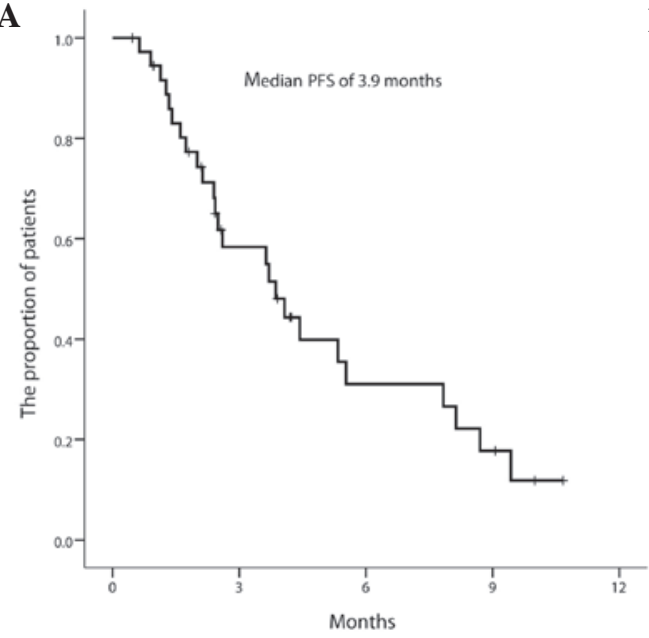

B

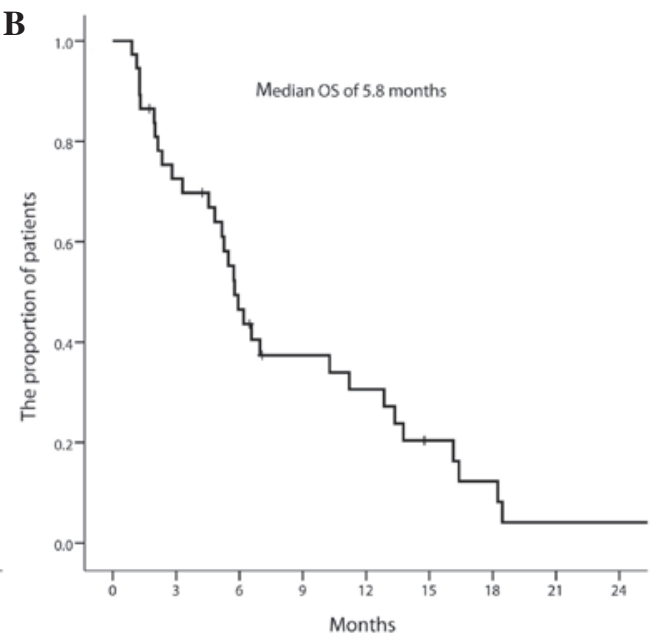

Figure 1. (A) Progression-free survival (PFS) in all enrolled patients. (B) Overall survival (OS) in all enrolled patients.

Clinicalcharacteristicsassociatedwithearlydiscontinuation. Early discontinuation ( $\leq 3$ cycles of chemotherapy without evident disease progression) occurred in 10 patients. Among those 10 patients, 8 dropped out early prior to first response assessment and 2 patients showed SD at first assessment and withdrew their consent for participation. The median age of the 10 patients who dropped out of the study was 64.5 years (range, 56-69 years), while the median age of the other 27 patients was 60.0 years (range, 40-70 years). The incidence of early discontinuation was associated with old age $(\mathrm{P}=0.036$; Fig. $2 \mathrm{~A})$ and a poor $\mathrm{PS}(\mathrm{P}=0.038$; Fig. $2 \mathrm{~B})$. A poor PS was observed in $6(60.0 \%)$ of the 10 early discontinuation patients compared with $5(18.5 \%)$ of the other 27 patients. However, the early discontinuation was not associated with other clinical characteristics, such as gender $(\mathrm{P}=0.229)$, percutaneous transhepatic biliary drainage insertion (0.404), stage $(\mathrm{P}=0.229)$, relapse $(\mathrm{P}=0.284)$, primary lesions $(\mathrm{P}=0.700)$ and metastatic site (liver, $\mathrm{P}=0.700$; peritoneum, $\mathrm{P}=0.214$; lung, $\mathrm{P}=0.303$; and distant lymph node, $\mathrm{P}=0.128$ ). Also, the incidence of grade $3 / 4$ neutropenia and thrombocytopenia was not associated with early discontinuation
( $\mathrm{P}=0.537$ and $\mathrm{P}=0.201$, respectively). The non-hematological toxicities could not be analyzed due to a low incidence in this study.

As old age and a poor PS were correlated with early discontinuation, the patients were separated into two groups: A high-risk group $(n=16$; age $\geq 65$ or $P S \geq 2)$ and a low-risk group ( $\mathrm{n}=21$; age $<65$ and PS $<2$ ). According to these criteria, the median PFS time was 2.4 months (95\% CI, 2.0-2.8) in the high-risk group and 5.3 months $(95 \% \mathrm{CI}, 2.9-7.7)$ in the low-risk group ( $\mathrm{P}=0.071 ; \mathrm{P}=0.021$ in Breslow test) (Fig. 3A). The median OS time was 2.8 months $(95 \% \mathrm{CI}, 0.5-5.1)$ in the high-risk group and 10.3 months $(95 \% \mathrm{CI}, 4.1-16.4)$ in the low-risk group ( $\mathrm{P}=0.047$; Fig. 3B).

\section{Discussion}

The triplet GFP chemotherapy showed an acceptable disease control rate $(24.1 \%$ for PR and $44.8 \%$ for SD) and a modest efficacy for median PFS and OS times (3.9 and 5.8 months, respectively). The 6-month PFS rate was $30.9 \%$ and the 1-year survival rate was $30.6 \%$. 
A

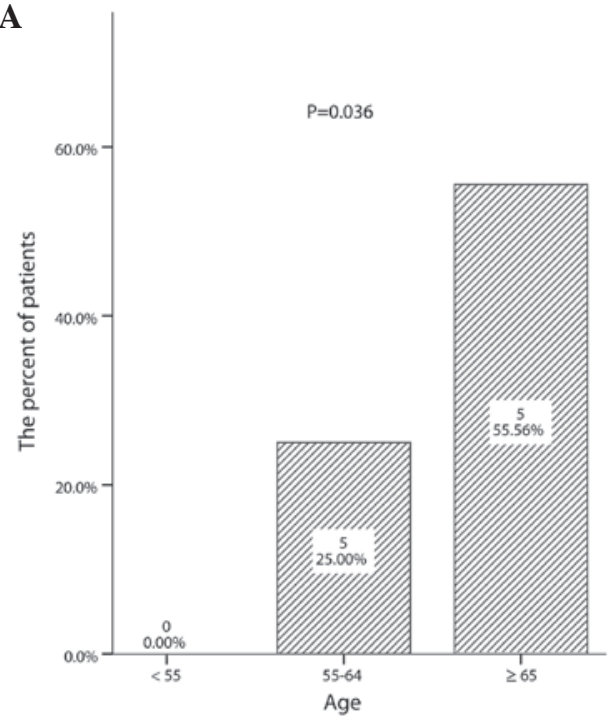

B

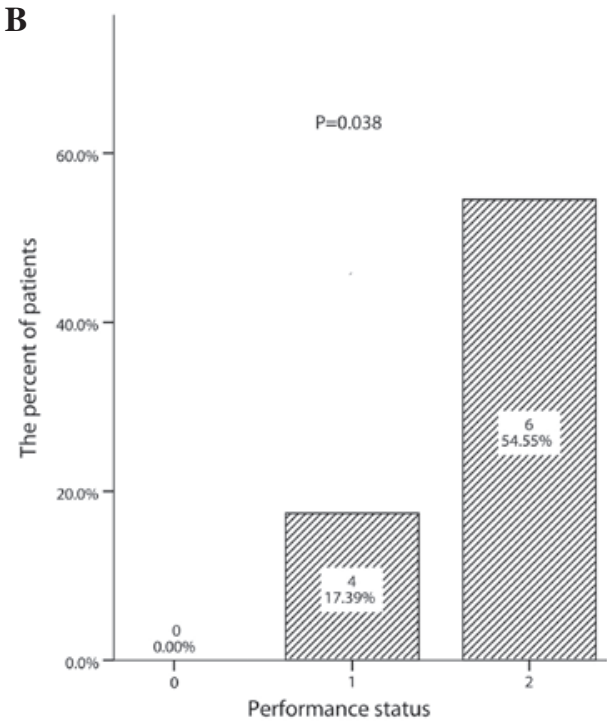

Figure 2. (A) Early discontinuation ( $\leq 3$ cycles of chemotherapy without marked disease progression) according to age group. (B) Early discontinuation ( $\leq 3$ cycles of chemotherapy without marked disease progression) according to performance status.

$\mathbf{A}$

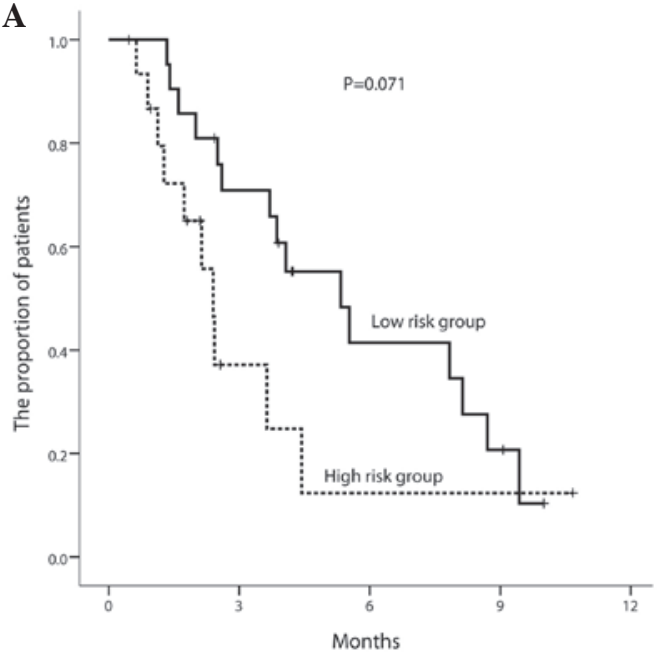

B

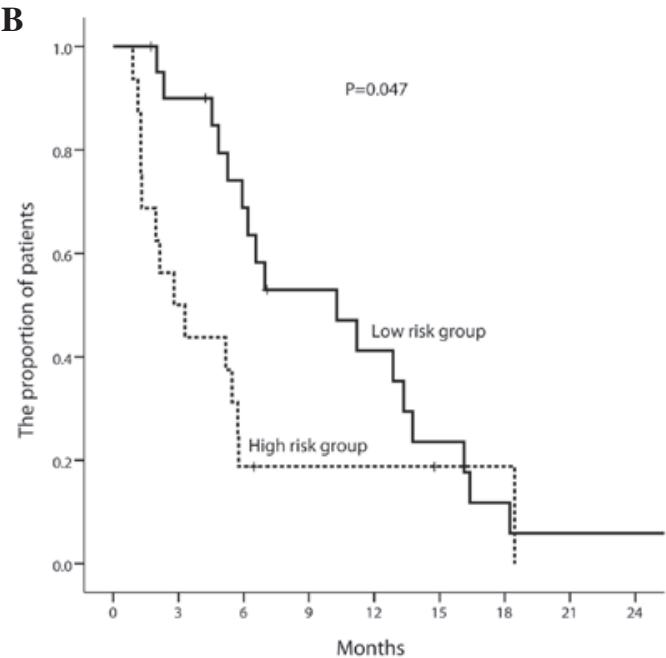

Figure 3. (A) Progression-free survival according to risk group for early discontinuation ( $\leq 3$ cycles of chemotherapy without marked disease progression). (B) Overall survival according to risk group for early discontinuation ( $\leq 3$ cycles of chemotherapy without marked disease progression).

In a recent phase III study, the folinic acid, 5-FU, irinotecan and oxaliplatin (FOLFIRINOX) regimen resulted in a 6-month PFS rate of $52.8 \%$ and a 1-year OS rate of $48.4 \%$ in advanced pancreatic cancer patients (26). However, gemcitabine monotherapy remains the reference regimen for advanced pancreatic cancer $(2,27)$, as the combination of gemcitabine with other cytotoxic drugs has not shown significant benefit, except in three studies (28-30). In phase II trials of triplet cytotoxic chemotherapy [i.e., gemcitabine/docetaxel/capecitabine, gemcitabine/oxaliplatin/5-FU, gemcitabine/5-FU/cisplatin (GFP) or mitomycin/docetaxel/irinotecan], the previously reported overall response rate was between 0 and $33.3 \%$ and the median OS time was between 6.1 and 14.5 months (31-35). Although the response rate in the present study was acceptable, the 5.9-month median OS time may appear to be inferior to those of the reported phase II triplet trials. However, if the time-point survival rate is compared with those of previously reported triplet trials, the $30.9 \%$ 1-year OS rate in the present study is comparable with the results of the previous phase II GFP trials with 1-year OS rates of 26-34\% $(34,35)$. As 10 patients in the present study experienced early discontinuation, which is a major cause of shortened median survival time, this discrepancy between time-point survival rate and median survival time may indicate that the major drawback of this triplet GFP regimen is the difficulty of long-term maintenance rather than the efficacy of treatment. Also, this discrepancy may explain why the median OS time of the GFP regimen in the present study appears to be inferior to that of previous duplet regimens, such as the combination of gemcitabine with cisplatin (7.1-8.3 months) (12-14,29,36), gemcitabine with oxaliplatin (9.2 months) (37), and gemcitabine with fluoropyrimidine (6.7-10.3 months) $(9,10,28,38)$.

To find the appropriate group for triplet GFP chemotherapy, selection of the low-risk and high-risk group for early discontinuation was performed according to age and PS. After grouping all the enrolled patients into the two risk groups, the low-risk 
group showed an acceptable 5.3-month median PFS time and a 10.3-month median OS time, which were comparable with previously reported duplet or triplet regimens. Although the performance scales are somewhat subjective, there is a possibility that the PS at the initiation of chemotherapy may be a predictor of poor tolerance in hematological toxicity to triplet GFP chemotherapy. Also, elderly patients $(\geq 65)$ adhered poorly to the triplet GFP chemotherapy. However, the exact reason is uncertain in the present study, as non-hematological toxicities could not be analyzed due to the low incidence in this study.

This triplet regimen showed substantial hematological toxicities. Grade 3/4 neutropenia and thrombocytopenia occurred in more than a half of the patients, who required subsequent dose reduction. This frequent grade 3/4 hematological toxicity may inevitably deteriorate the general medical condition of vulnerable patients with a poor PS, and this probably caused early discontinuation prior to even attaining any clinical benefits. As the study showed that the a poor PS was associated with more frequent hematological toxicities, careful monitoring of the CBC and prophylactic G-CSF use may be suggested during chemotherapy.

In conclusion, the GFP regimen has comparable activity to gemcitabine-based single or duplet chemotherapy in disease control, and modest efficacy in survival. This triplet GFP chemotherapy caused substantial hematological toxicity and a high rate of early discontinuation in the patients with an old age and poor PS. However, even when considering the result found in the younger patients with a good PS, these results do not appear to have marked superiority to gemcitabine-based single or duplet chemotherapy.

\section{References}

1. Heinemann V: Gemcitabine: Progress in the treatment of pancreatic cancer. Oncology 60: 8-18, 2001.

2. Burris HA III, Moore MJ, Andersen J, Green MR, Rothenberg M1, Modiano MR, Cripps MC, Portenoy RK, Storniolo AM, Tarassoff P, et al: Improvements in survival and clinical benefit with gemcitabine as first-line therapy for patients with advanced pancreas cancer: A randomized trial. J Clin Oncol 15: 2403-2413, 1997.

3. Carmichael J, Fink U, Russell RC, Spittle MF, Harris AL, Spiessi G and Blatter J: Phase II study of gemcitabine in patients with advanced pancreatic cancer. Br J Cancer 73: 101-105, 1996.

4. Crinò L, Mosconi AM, Calandri C, Corgna E, Porrozzi S, Chiara S, Nobili MT and Tonato M: Gemcitabine in advanced pancreatic cancer: A phase II trial. Am J Clin Oncol 24: 296-298, 2001.

5. Rocha Lima CM, Savarese D, Bruckner H, Dudek A, Eckardt J, Hainsworth J, Yunus F, Lester E, Miller W, Saville W, et al: Irinotecan plus gemcitabine induces both radiographic and CA 19-9 tumor marker responses in patients with previously untreated advanced pancreatic cancer. J Clin Oncol 20: 1182-1191, 2002.

6. Stathopoulos GP, Mavroudis D, Tsavaris N, Kouroussis C, Aravantinos G, Agelaki S, Kakolyris S, Rigatos SK, Karabekios S and Georgoulias V: Treatment of pancreatic cancer with a combination of docetaxel, gemcitabine and granulocyte colony-stimulating factor: A phase II study of the Greek Cooperative Group for Pancreatic Cancer. Ann Oncol 12: 101-103, 2001

7. Shepard RC, Levy DE, Berlin JD, Stuart K, Harris JE, Aviles V, Thomas JP and Benson AB III: Phase II Study of gemcitabine in combination with docetaxel in patients with advanced pancreatic carcinoma (E1298). A trial of the eastern cooperative oncology group. Oncology 66: 303-309, 2004.

8. Oettle H, Arning M, Pelzer U, Arnold D, Stroszczynski C, Langrehr J, Reitzig P, Kindler M, Herrenberger J, Musch R, et al: A phase II trial of gemcitabine in combination with 5-fluorouracil (24-hour) and folinic acid in patients with chemonaive advanced pancreatic cancer. Ann Oncol 11: 1267-1272, 2000.
9. Hidalgo M, Castellano D, Paz-Ares L, Gravalos C, Diaz-Puente M, Hitt R, Alonso S and Cortes-Funes H: Phase I-II study of gemcitabine and fluorouracil as a continuous infusion in patients with pancreatic cancer. J Clin Oncol 17: 585-592, 1999.

10. Berlin JD, Catalano P, Thomas JP, Kugler JW, Haller DG and Benson AB III: Phase III Study of gemcitabine in combination with fluorouracil versus gemcitabine alone in patients with advanced pancreatic carcinoma: Eastern Cooperative Oncology Group Trial E2297. J Clin Oncol 20: 3270-3275, 2002.

11. Wils JA, Kok T, Wagener DJT, Selleslags J and Duez N: Activity of cisplatin in adenocarcinoma of the pancreas. Eur J Cancer 29A: 203-204, 1993.

12. Heinemann V, Wilke H, Mergenthaler HG, Clemens M, König H, Illiger HJ, Arning M, Schalhorn A, Possinger K and Fink U: Gemcitabine and cisplatin in the treatment of advanced or metastatic pancreatic cancer. Ann Oncol 11: 1399-1403, 2000.

13. Colucci G, Giuliani F, Gebbia V, Biglietto M, Rabitti P, Uomo G, Cigolari S, Testa A, Maiello E and Lopez M: Gemcitabine alone or with cisplatin for the treatment of patients with locally advanced and/or metastatic pancreatic carcinoma: A prospective, randomized phase III study of the Gruppo Oncologia dell'Italia Meridionale. Cancer 94: 902-910, 2002.

14. Philip PA,Zalupski MM, Vaitkevicius VK, Arlauskas P, Chaplen R, Heilbrun LK, Adsay V, Weaver D and Shields AF: Phase II study of gemcitabine and cisplatin in the treatment of patients with advanced pancreatic carcinoma. Cancer 92: 569-577, 2001.

15. Bruckner HW, Zhou G, Haenel P, Szrajer L, Greenspan E and Kurbacher C: Ex vivo ATP tumor testing of gemcitabine for combination chemotherapy and biochemical modulation. Proc Am Assoc Cancer Res 39: 310a (abstract 2116), 1998.

16. Bergman AM, Ruiz van Haperen VW, Veerman G, Kuiper CM and Peters GJ: Synergistic interaction between cisplatin and gemcitabine in vitro. Clin Cancer Res 2: 521-530, 1996.

17. Peters GJ, Ruiz van Haperen VW, Bergman AM, Veerman G, Smitskamp-Wilms E, van Moorsel CJ, Kuiper CM and Braakhuis BJ: Preclinical combination therapy with gemcitabine and mechanisms of resistance. Semin Oncol 23 (Suppl 10): 16-24, 1996.

18. Peters GJ, Bergman AM, Ruiz van Haperen VW, Veerman G, Kuiper CM and Braakhuis BJ: Interaction between cisplatin and gemcitabine in vitro and in vivo. Semin Oncol 22 (Suppl 11): 72-79, 1995.

19. Peters GJ, Bergman AM, Veerman G and Ruiz van Haperen VWT: Synergism between cisplatin and gemcitabine $(\mathrm{dFdC})$ in resistant A2780 human ovarian cancer cell lines is schedule dependent. Proc Am Assoc Cancer Res 35: 1950 (abstract), 1994.

20. Braakhuis BJM, Ruiz van Haperen VWT, Bergman AM, Welters MJP and Peters GJ: Preclinical in vivo evaluation of the combination of 2,3 difluorodeoxycytidine ( $\mathrm{dFdC}$, gemcitabine) and cisplatin (CDDP). Ann Oncol 5: 82 (abstract 054), 1994.

21. Schabel FM Jr, Trader MW, Laster WR Jr, Corbett TH and Griswold DP Jr: cis-Dichlorodiammineplatinum(II): Combination chemotherapy and cross-resistance studies with tumors of mice. Cancer Treat Rep 63: 1459-1473, 1979.

22. Greene F, Page D, Fleming I, Fritz A, Balch C, Haller D and Morrow M (eds): AJCC Cancer Staging Manual. 6th edition. Springer, New York, NY, USA, pp157-161, 2002.

23. Oken MM, Creech RH, Tormey DC, Horton J, Davis TE, McFadden ET and Carbone PP: Toxicity and response criteria of the Eastern Cooperative Oncology Group. Am J Clin Oncol 5: 649-655, 1982

24. Miller AB, Hoogstraten B, Staquet M and Winkler A: Reporting results of cancer treatment. Cancer 47: 207-214, 1981.

25. Fleming TR: One-sample multiple testing procedure for phase II clinical trials. Biometrics 38: 143-151, 1982.

26. Conroy T, Desseigne F, Ychou M, Bouché O, Guimbaud R, Bécouarn Y, Adenis A, Raoul JL, Gourgou-Bourgade S, de la Fouchardière $\mathrm{C}$, et al: FOLFIRINOX versus gemcitabine for metastatic pancreatic cancer. N Engl J Med 364: 1817-1825, 2011.

27. Di Marco M, Di Cicilia R, Macchini M, Nobili E, Vecchiarelli S, Brandi G and Biasco G: Metastatic pancreatic cancer: Is gemcitabine still the best standard treatment? (Review). Oncol Rep 23: 1183-1192, 2010.

28. Herrmann R, Bodoky G, Ruhstaller T, Glimelius B, Bajetta E, Schüller J, Saletti P, Bauer J, Figer A, Pestalozzi B, et al: Gemcitabine plus capecitabine compared with gemcitabine alone in advanced pancreatic cancer: A randomized, multicenter, phase III trial of the Swiss Group for Clinical Cancer Research and the Central European Cooperative Oncology Group. J Clin Oncol 25: 2212-2217, 2007. 
29. Heinemann V, Quietzsch D, Gieseler F, Gonnermann M, Schönekäs H, Rost A, Neuhaus H, Haag C, Clemens M, Heinrich B, et al: Randomized phase III trial of gemcitabine plus cisplatin compared with gemcitabine alone in advanced pancreatic cancer. J Clin Oncol 24: 3946-3952, 2006.

30. Heinemann V, Boeck S, Hinke A, Labianca R and Louvet C: Meta-analysis of randomized trials: Evaluation of benefit from gemcitabine-based combination chemotherapy applied in advanced pancreatic cancer. BMC Cancer 8: 82, 2008.

31. Reni M, Panucci MG, Passoni P, Bonetto E, Nicoletti R, Ronzoni M, Zerbi A, Staudacher C, Di Carlo V and Villa E: Salvage chemotherapy with mitomycin, docetaxel, and irinotecan (MDI Regimen) in metastatic pancreatic adenocarcinoma: A Phase I and II Trial. Cancer Invest 22: 688-696, 2004.

32. Fine R, Moorer G, Sherman W, et al: Phase II trial of GTX chemotherapy in metastatic pancreatic cancer. J Clin Oncol 27 (Suppl 15): abstract 4623, 2009.

33. Correale P, Montagnani F, Miano S, Sciandivasci A, Pascucci A, Petrioli R, Testi W, Tanzini G and Francini G: Biweekly triple combination chemotherapy with gemcitabine, oxaliplatin, levofolinic acid and 5-fluorouracil (GOLF) is a safe and active treatment for patients with inoperable pancreatic cancer. J Chemother 20: 119-125, 2008.
34. El-Rayes BF, Zalupski MM, Shields AF, Vaishampayan U, Heilbrun LK, Jain V, Adsay V, Day J and Philip PA: Phase II study of gemcitabine, cisplatin, and infusional fluorouracil in advanced pancreatic cancer. J Clin Oncol 21: 2920-2925, 2003.

35. Novarino A, Chiappino I, Bertelli GF, Heouaine A, Ritorto G, Addeo A, Bellone G, Merlano M and Bertetto O: Phase II study of cisplatin, gemcitabine and 5-fluorouracil in advanced pancreatic cancer. Ann Oncol 15: 474-477, 2004

36. Colucci G, Labianca R, Di Costanzo F, Gebbia V, Cartenì G, Massidda B, Dapretto E, Manzione L, Piazza E, Sannicolò $\mathrm{M}$, et al: Randomized phase III trial of gemcitabine plus cisplatin compared with single-agent gemcitabine as first-line treatment of patients with advanced pancreatic cancer: The GIP-1 study. J Clin Oncol 28: 1645-1651, 2010.

37. Louvet C, André T, Lledo G, Hammel P, Bleiberg H, Bouleuc C, Gamelin E, Flesch M, Cvitkovic E and de Gramont A: Gemcitabine combined with oxaliplatin in advanced pancreatic adenocarcinoma: Final results of a GERCOR multicenter phase II study. J Clin Oncol 20: 1512-1518, 2002.

38. Di Costanzo F, Carlini P, Doni L, Massidda B, Mattioli R, Iop A, Barletta E, Moscetti L, Recchia F, Tralongo P, et al: Gemcitabine with or without continuous infusion 5-FU in advanced pancreatic cancer: A randomised phase II trial of the Italian oncology group for clinical research (GOIRC). Br J Cancer 93: 185-189, 2005. 